I NRA Prod. Anim., 1999, 12 (4), 287-300
Y. FAULCONNIER ${ }^{1}$, M. BONNET ${ }^{1}$, F. BOCQUIER ${ }^{1,2}$, C. LEROUX ${ }^{3}$, J. F. HOCQUETTE ${ }^{4}$, P. MARTIN ${ }^{3}$, Y. CHILLIARD

${ }^{1}$ I NRA Uni té de Recherche sur les Herbi vores, Equipe Tissu Adipeux et Li pi des du Lait,

Thei x, 63122 St Genès Champanelle ${ }^{2}$ Adresse actuelle: ENSA.M-INRA Productions Ani males, 2 place Viala, 34060 Montpelli er Cedex

3 INRA Laboratoi re de Généti que Bi ochi mi que et de Cytogéni ti que, 78352 J ouy-en-J osas Cedex ${ }^{4}$ INRA, Uni té de Recherche sur les Métabolismes du Muscle, Thei x, 63122 St Genès Champanelle

e-mai I : Yves.Chilliard@dermont.inra.fr Herbi vores, Equi pe Croissance et

\section{Régulation du métabolisme lipidique des tissus adipeux et musculaires chez le ruminant. E ffets du niveau alimentaire et de la photopériode}

L'aptitude des ruminants à mobiliser et à reconstituer leurs réserves lipidiques est largement utilisée dans les systèmes d'élevage pour tenir compte des variations des disponibilités alimentaires et des modifications des besoins des animaux au cours du cycle de production. Cet article fait le point sur les mécanismes qui régulent le métabolisme des lipides, et notamment la répartition des nutriments entre tissus adipeux et tissus musculaires, en fonction des conditions d'alimentation et également, pour les ovins, de la photopériode.

\section{Résumé}

Les effets respectifs de l'état nutritionnel et de la photopériode sur le métabolisme lipidique et le partage de nutriments entre le tissu adipeux et le muscle sont récapitulés chez le ruminant, en particulier pour ce qui concerne l'expression des gènes spécifiant les enzymes lipogéniques et la lipoprotéinelipase chez la vache et la brebis. La restriction alimentaire diminue la synthèse de novo d'acides gras et l'activité lipoprotéine-lipasique dans les tissus adipeux des ruminants adultes ou en croissance. Ces effets sont partiellement ou totalement inversés par la réalimentation. Chez les ovins et les bovins adultes, l'activité lipoprotéine-lipasique est diminuée par la restriction dans le muscle cardiaque, oxydatif, inchangée dans le muscle Longissimus thoracis, glycolytique, et augmentée par la réalimentation dans ces deux muscles. Les activités lipoprotéine-lipasiques du tissu adipeux et du muscle de ruminant répondent donc dans le même sens à des variations de l'état nutritionnel, contrairement aux données généralement publiées chez le rat. De plus, les taux d'AR Nm de la lipoprotéine-lipase dans le tissu adipeux et le muscle varient de manières identiques à son activité chez les différentes espèces, ce qui suggère une régulation, au moins en partie, pré-traductionnelle de l'expression du gène spécifiant cette enzyme. La photopériode exerce une influence directe sur l'activité métabolique des tissus adipeux et musculaires de brebis. Ainsi, les capacités lipogéniques du tissu adipeux et l'activité lipoprotéine-lipasique du muscle glycolytique sont augmentées par les jours longs. Inversement, la lipomobilisation est augmentée par les jours courts. Ces adaptations métaboliques sont probablement impliquées dans les adaptations physiologiques des ovins aux variations saisonnières des disponibilités alimentaires.
Au cours du cycle de production, les femelles des ruminants sont soumises à des périodes de sous-nutrition de durée et d'intensité variables, induites par des fluctuations des besoins énergétiques et des apports nutritionnels. Chez le bovin producteur de viande, la croissance compensatrice est un mode de conduite classiquement appliqué en élevage extensif en fonction des fluctuations saisonnières des ressources alimentaires. Les périodes de restriction alimentaire sont marquées par l'utilisation des réserves lipidiques de l'organisme qui jouent alors un rôle considérable dans le maintien de la productivité des animaux. La survie de I'animal au cours des cycles successifs d'apports alimentaires variables suppose que les tissus adipeux mobilisés (lipolyse) soient ensuite efficacement reconstitués (lipogenèse) lors des périodes de fortes disponibilités alimentaires.

La lipolyse correspond à la dégradation des triglycérides, et la lipogenèse à leur formation, celle-ci résultant de trois voies métaboliques : la synthèse de novo d'acides gras, le captage d'acides gras après hydrolyse des triglycérides circulants et l'estérification de ces 
acides gras, qui sont ensuite stockés dans la cellule adipeuse. Les cycles de mobilisation et de reconstitution des réserves lipidiques modifient les teneurs du muscle en glycogène et en triglycérides qui déterminent repectivement le pH ultime de la viande et la flaveur de celle-ci (Hocquette et al 1998a et 1998b).

Cette faculté d'utilisation et de reconstitution des réserves lipidiques constitue une adaptation des ruminants aux variations de leur environnement. Or, la durée quotidienne d'éclairement (photopériode), qui varie au cours des saisons, agit sur la reproduction et sur l'appétit des petits ruminants. Du fait des modifications saisonnières des disponibilités alimentaires, en relation avec le climat et la photopériode, et des besoins induits par la gestation et la lactation, les masses adipeuses des ovins subissent des variations saisonnières importantes (Bocquier et al 1986 et 1990, Vernon et al 1986). Toutefois, il n'existe que très peu de données sur un éventuel effet direct de la durée d'éclairement (indépendamment de tout effet sur la prise alimentaire) sur les enzymes impliquées dans le métabolisme du tissu adipeux et le prélèvement des substrats énergétiques par le muscle (revue de Chilliard et Bocquier 1999).

L'objectif de cet article est de présenter les résultats disponibles concernant les effets de la sous-alimentation, de la réalimentation et de la photopériode sur le métabolisme lipidique, et notamment sur les activités d'enzymes impliquées dans la répartition des nutriments énergétiques entre les tissus adipeux et musculaires. Nous nous sommes surtout intéressés à la lipoprotéine-lipase, enzyme impliquée dans le captage des acides gras issus des triglycérides circulants, à la fois dans tissu adipeux (stockage principalement) et dans le muscle (oxydation principalement), mais également à d'autres enzymes lipogéniques jouant un rôle important dans le tissu adipeux.

La capacité lipogénique varie selon la localisation des tissus adipeux, en interaction avec l'effet de facteurs nutritionnels chez les ruminants (Haugebak et al 1974, Prior et Scott 1980, Tume et al 1983, Chilliard et Robelin 1985) ou de la photopériode chez une espèce photosensible comme le hamster (Youngstrom et Bartness 1995). En outre, dans le muscle, les modifications de l'activité lipoprotéine-lipasique induite par l'état nutritionnel sont très variables chez les espèces monogastriques, surtout en fonction du type métabolique de muscle (oxydatif vs glycolytique). Chez les ruminants, les effets du niveau alimentaire et de la photopériode sur l'activité lipogénique et l'expression du gène de la lipoprotéine-lipase sont donc décrits dans un site de tissu adipeux externe, le tissu adipeux sous- cutané, et dans un site de tissu adipeux interne, le tissu adipeux périrénal, ainsi que dans deux muscles aux caractéristiques métaboliques extrêmes, le muscle cardiaque (classiquement utilisé pour les études réalisées chez le rat), oxydatif, et un muscle glycolytique, le muscle Longi ssimus thoracis. Certains résultats et concepts développés chez les espèces monogastriques sont aussi présentés dans cette revue afin de faciliter
I'interprétation des résultats obtenus chez les ruminants.

\section{1 / Régulation nutritionnelle du métabolisme lipidique tissulaire}

\section{1 / Synthèse d'acides gras par le tissu adipeux}

\section{a / Activités lipogéniques}

Le niveau alimentaire a des conséquences importantes sur le profil hormonal et métabolique des animaux (Chilliard et al 1995) et, de ce fait, sur l'activité lipogénique du tissu adipeux, que ce soit chez le ruminant adulte ou en croissance. Chez le ruminant en croissance, un jeûne de 8 jours diminue la synthèse d'acides gras d'environ $98 \%$, les activités des enzymes lipogéniques (acétyl-CoA carboxylase et synthéthase des acides gras) diminuant elles aussi fortement (tableau 1). Ces effets semblent toutefois être moins marqués lorsque le jeûne ne dure que 4 jours. Les activités des autres enzymes impliquées dans la synthèse de novo (glucose-6-phosphate déshydrogénase et enzyme malique) ou dans l'esterification (glycérol-3-phosphate déshydrogénase) des acides gras diminuent également après un jeûne de 8 jours. Chez le ruminant adulte, une sous-alimentation de 7 jours (apports égaux à $20 \%$ du besoin d'entretien des animaux) diminue l'ensemble des activités lipogéniques mesurées, mais de façon moins marquée chez les bovins que chez les ovins (tableau 1). Par ailleurs, l'effet de la sous-nutrition sur les activités lipogéniques est comparable quel que soit le site de tissu adipeux chez les ovins adultes ou en croissance. Cet effet est toutefois moins marqué au niveau du tissu adipeux sous-cutané qu'au niveau du tissu adipeux périrénal chez les bovins adultes (tableau 1) alors qu'il semble identique chez les bovins en croissance (Pothoven et Beitz 1973).

Après une période de jeûne, la réalimentation se traduit par une augmentation de la synthèse d'acides gras à partir de l'acétate et des activités des enzymes lipogéniques (tableau 1). L'amplitude de variations des activités lipogéniques semble étroitement liée à la durée mais également au niveau de réalimentation. Ainsi, chez le bovin en croissance réalimenté ad li bi tum durant 16 jours, la synthèse d'acides gras et les activités des enzymes lipogéniques augmentent dans le tissu adipeux sous-cutané alors qu'aucune augmentation n'est observée dans le même site de tissu adipeux chez des agneaux réalimentés pendant 8 jours à $80 \%$ seulement de leurs besoins (tableau 1). Plusieurs auteurs ont d'ailleurs montré une corrélation positive $(r=0,48$ à 0,79$)$ entre la capacité lipogénique du tissu adipeux et le niveau alimentaire ou le bilan énergétique chez les ruminants (Prior 1978, Giménez et al 1985, Chilliard et al 1987, Mills et al 1989, Smith et al 1992, Sebastian et al 1993). Une forte réalimentation (à $200 \%$ du 
Tableau 1. Effets de la sous-alimentation (en \% des valeurs mesurées chez les animaux témoins) et de la réalimentation (en \% des valeurs mesurées chez les animaux à jeun ou sous-alimentés) sur les activités d'enzymes lipogéniques dans les tissus adipeux de ruminants en croissance ou adultes.

\begin{tabular}{|c|c|c|c|c|c|c|c|}
\hline \multirow[b]{2}{*}{ Tissu adipeux } & \multicolumn{2}{|c|}{ Bouvillons ${ }^{(1,2)}$} & \multicolumn{2}{|c|}{ Vaches ${ }^{(3)}$} & \multirow{3}{*}{$\begin{array}{l}\text { Agneaux } \\
\text { sous-cutané } \\
\text { Jeûne 8j }\end{array}$} & \multicolumn{2}{|c|}{ Brebis ${ }^{(5)}$} \\
\hline & sous-cutané & sous-cutané & périrénal & sous-cutané & & périrénal & sous-cutané \\
\hline Sous-alimentation & Jeûne 8 j (1) & Jeûne 4 j (2) & Sous-alim.7 j & Sous-alim. $7 \mathrm{j}$ & & Sous-alim.7 j & Sous-alim. $7 \mathrm{j}$ \\
\hline $\begin{array}{l}\text { Synthèse d'acides gras } \\
\text { Acétyl-CoA carboxylase } \\
\text { Synthétase des acides gras } \\
\text { Glucose-6-P déshydrogénase } \\
\text { Glycérol-3-P déshydrogénase } \\
\text { Enzyme malique }\end{array}$ & $\begin{array}{l}-98 \\
-97 \\
-67\end{array}$ & $\begin{array}{l}-53 \\
-26 \\
-4\end{array}$ & $\begin{array}{l}-33 \\
-39 \\
-17 \\
-33\end{array}$ & $\begin{array}{l}+16 \\
+7 \\
+14 \\
+19\end{array}$ & $\begin{array}{l}-98 \\
-80 \\
-57 \\
-32 \\
-38\end{array}$ & $\begin{array}{l}-62 \\
-61 \\
-50 \\
-41\end{array}$ & $\begin{array}{l}-38 \\
-67 \\
-41 \\
-33\end{array}$ \\
\hline Réalimentation & $16 j^{(1)}$ & $14 j^{(2)}$ & $21 \mathrm{j}$ & $21 \mathrm{j}$ & $8 \mathrm{j}$ & $14 \mathrm{j}$ & $14 \mathrm{j}$ \\
\hline $\begin{array}{l}\text { Synthèse d'acides gras } \\
\text { Acétyl-CoA carboxylase } \\
\text { Synthéthase des acides gras } \\
\text { Glucose-6-P déshydrogénase } \\
\text { Glycérol-3-P déshydrogénase } \\
\text { Enzyme malique }\end{array}$ & $\begin{array}{l}+4100 \\
+3900 \\
+130\end{array}$ & $\begin{array}{c}+300 \\
+40\end{array}$ & $\begin{array}{l}+240 \\
+300 \\
+110 \\
+290\end{array}$ & $\begin{array}{l}+140 \\
+90 \\
+80 \\
+35\end{array}$ & $\begin{array}{l}+365 \\
+33 \\
+4 \\
-28 \\
-20\end{array}$ & $\begin{array}{l}+380 \\
+280 \\
+100 \\
+120\end{array}$ & $\begin{array}{l}+340 \\
+330 \\
+160 \\
+200\end{array}$ \\
\hline
\end{tabular}

(1) Pothoven et Beitz 1975, (2) Smith et al 1983, (3) Faulconnier et al 1998, (4) Ingle et al 1973, (5) Chilliard et al $1998 \mathrm{~b}$ et Faulconnier et al 1998.

besoin des animaux) durant 14 jours (brebis) ou 21 jours (vaches) augmente l'ensemble des activités des enzymes lipogéniques dans les tissus adipeux bovin et ovin (de +100 a $+380 \%$, sauf dans le tissu adipeux sous-cutané bovin, pour lequel l'amplitude des variations n'excède pas $+35 \%$ à $+140 \%$; tableau 1). Ces augmentations rétablissent les activités lipogéniques à des niveaux supérieurs (+ 31 à + $180 \%$ ) à ceux observés chez les animaux témoins. Le niveau et la durée de réalimentation (au moins deux semaines) sont donc deux facteurs essentiels pour que les activités lipogéniques fortement diminuées par une sous-alimentation reviennent à des valeurs comparables à celles mesurées chez des animaux témoins. Par ailleurs et symétriquement à ce qui a été observé lors de la sous-nutrition, l'effet de la réalimentation est identique quel que soit le site de tissu adipeux chez la brebis. Chez le bovin adulte, le tissu adipeux sous-cutané répond moins bien que le tissu adipeux périrénal (tableau 1), alors que l'inverse est observé chez le bovin en croissance (Pothoven et Beitz 1975, Prior et Scott 1980).

\section{b / Niveau de régulation des activités lipogéniques}

Les résultats disponibles chez le rat montrent une relation positive entre les variations des activités des enzymes lipogéniques et celles des taux d'ARNm spécifiant ces enzymes. En effet, chez des rats préalablement mis à jeun durant 24 à 72 heures, une réalimentation à base de glucides durant 24 à 72 heures augmente les activités acétyl-CoA carboxylase, synthéthase des acides gras, glucose-6-phosphate déshydrogénase et enzyme malique du tissu adipeux épididymaire en augmentant (de 9 à 50 fois) leur taux d'ARNm spécifique (Pape et al 1988, Irritani et al 1996, Kim et Freake 1996). Des résultats similaires sont observés pour la synthéthase des acides gras du tissu adipeux perirénal de vache et de brebis sous-alimentées puis réalimentées (Bonnet et al 1998a) ce qui suggère une régulation au moins en partie pré-traductionnelle de l'expression du gène de cette enzyme chez les ruminants, comme chez les monogastriques.

\section{2 / Prélèvement d'acides gras par les tissus adipeux et musculaires : activité de la lipoprotéine-lipase}

La lipoprotéine-lipase est une glycoprotéine synthétisée et sécrétée par de nombreux tissus extra-hépatiques. Cette enzyme hydrolyse les triglycérides contenus dans les lipoprotéines de très faible densité. Les acides gras ainsi libérés sont captés en grande partie par ces tissus et principalement par les tissus adipeux et musculaires.

\section{a / Activité lipoprotéine-lipasique dans les tissus adipeux}

Le jeûne diminue l'activité de la lipoprotéine-lipase dans le tissu adipeux de la plupart des espèces monogastriques alors qu'une réalimentation l'augmente, quelle que soit la durée du traitement alimentaire (figure 1). Chez les ruminants, le jeûne ou la sous-nutrition diminue de 55 à $96 \%$ l'activité de la lipoprotéine-lipase du tissu adipeux, quelles que soient l'espèce et le site anatomique; la réalimentation l'augmente fortement $(+236$ à $1542 \%)$, avec de fortes variations selon les expérimentations, mais qui ne semblent pas liées à l'espèce ni au site anatomique (tableau 2). 
Figure 1. Variations de l'activité lipoprotéine-lipasique dans le tissu adipeux des espèces monogastriques en réponse à différentes durées de jeûne et à la réalimentation (synthèse de données bibliographiques : Bonnet 1999).

L'effet du jeûne concerne la comparaison de l'activité chez des animaux à jeun et chez des animaux alimentés ad libitum. L'effet de la réalimentation concerne la comparaison de l'activité chez des animaux alimentés ad libitum après une période de jeûne.

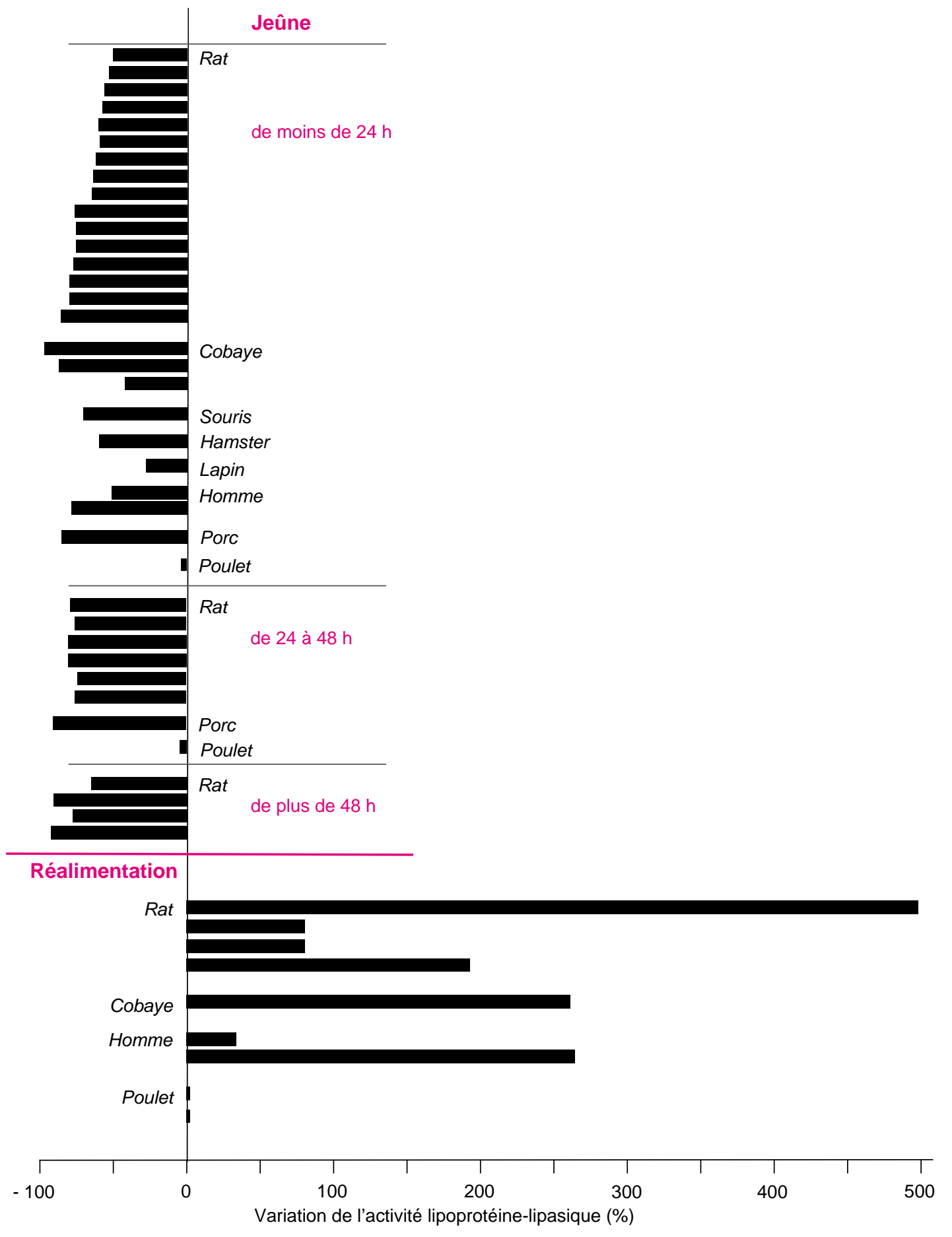

\section{b / Activité lipoprotéine-lipa sique dans les tissus musculaires}

Chez les monogastriques, les effets du jeûne et de la réalimentation sur l'activité lipoprotéine-lipasique dans les muscles sont variables selon le type métabolique du muscle étudié, l'espèce animale et les conditions expérimentales (figure 2). Dans le muscle car- diaque, de type oxydatif, le jeûne diminue l'activité lipoprotéine-lipasique chez le porc $(-40 \%)$, l'augmente de 42,80 et $250 \%$ chez le lapin, le hamster et le poulet respectivement, et n'a pas d'effet chez le cobaye ou la souris. Chez le rat, les résultats varient selon la durée des traitements alimentaires : un jeûne de moins de 24 heures augmente (de 25 à $350 \%$ ) l'activité lipoprotéine-lipasique dans le 
Tableau 2. Effets de la sous-alimentation (en \% des valeurs mesurées chez les animaux témoins) et de la réalimentation (en \% des valeurs mesurées chez les animaux à jeun ou sous-alimentés) sur l'activité lipoprotéine-lipasique (exprimée par gamme de tissu) dans les tissus adipeux et musculaires des ruminants.

\begin{tabular}{|c|c|c|}
\hline & Sous-alimentation & Réalimentation \\
\hline \multicolumn{3}{|c|}{ Tissus adipeux } \\
\hline \multicolumn{3}{|l|}{ Bouvillon } \\
\hline sous-cutané(1) & -66 & +450 \\
\hline \multicolumn{3}{|l|}{ Vache } \\
\hline sous-cutané(2) & -55 & +236 \\
\hline péri rénal ${ }^{(2,3)}$ & $-70^{(2)}$ & $+450^{(2)}$ ou $+972^{(3)}$ \\
\hline \multicolumn{3}{|l|}{ Agneau $^{(4)}$} \\
\hline sous-cutané & -96 & \\
\hline péri rénal & -89 & \\
\hline omental & -93 & \\
\hline \multicolumn{3}{|l|}{ Brebis } \\
\hline sous-cutané(5) & -82 & +782 \\
\hline péri rénal ${ }^{(3,6)}$ & $-56^{(6)}$ & $+288^{(3)}$ ou $+1542^{(6)}$ \\
\hline \multicolumn{3}{|l|}{ Chèvre $^{(7)}$} \\
\hline omental & & +1100 \\
\hline \multicolumn{3}{|c|}{ Muscle cardiaque (oxy datif) } \\
\hline Vache $^{(2)}$ & -66 & +258 \\
\hline Brebis $^{(6)}$ & -32 & +34 \\
\hline \multicolumn{3}{|c|}{$\begin{array}{l}\text { Muscle squelettique (glycolytique) } \\
\text { Longissimus thoracis }\end{array}$} \\
\hline Vache $^{(2)}$ & -11 & +48 \\
\hline Brebis $^{(5)}$ & -15 & +40 \\
\hline
\end{tabular}

(1) Jeûne de 9 jours puis réalimentation de 41 jours (DiMarco et al 1981)

(2) Sous-alimentation de 7 jours puis réalimentation de 21 jours (Faulconnier et al 1999)

(3) Sous-alimentation de 10 jours puis réalimentation de 21 jours (vaches), sous-alimentation de 8 jours puis réalimentation de 10 jours (brebis) (Bonnet et al 1998)

(4) J eûne de 4 jours (Tume et al 1983)

(5) Sous-alimentation de 7 jours puis réalimentation de 14 (brebis) ou de 21 jours (vaches) (Faulconnier et al 1998)

(6) Sous-alimentation de 7 jours puis réalimentation de 14 jours (Bonnet et al 1999)

(7) J eûne de 2 jours puis réalimentation de 7 jours (Chilliard et al 1979).

muscle cardiaque alors qu'un jeûne supérieur à 24 heures n'a généralement pas d'effet. Après un jeûne de 16 à 24 heures, la réalimentation pendant 12 à 24 heures ne modifie pas significativement l'activité lipoprotéinelipasique tissulaire du cœur de rat (figure 2).

Dans les muscles squelettiques oxydatifs, comme le soleus (contenant $84 \%$ de fibres oxydatives), un jeûne de 24 heures augmente (de +110 à $+297 \%$ ) l'activité lipoprotéinelipasique chez des rats âgés d'un mois (Quig et al 1983, Sudgen et al 1993, Bergö et al 1997), mais n'a pas d'effet chez des rats plus âgés (Ladu et al 1991, Ong et al 1994, Bergö et al 1997). Après un jeûne de 24 heures, la réalimentation ad libitum pendant 24 heures diminue (- $56 \%$ ) cette activité chez les rats âgés d'un mois (Quig et al 1983).

Dans les muscles squelettiques glycolytiques, tels que l'extensor di gi torum longus (composé pour $97 \%$ de fibres glycolytiques) ou le psoas (à prédominance de fibres glycoIytiques), un jeûne de 12 à 120 heures n'induit pas de modification de l'activité lipoprotéinelipasique chez le rat (Tan et al 1977, Quig et al 1983, Sudgen et al 1993, Ong et al 1994).
Aucun effet significatif n'est par ailleurs observé chez des rats à jeun durant 24 heures puis réalimentés ad li bi tum (Quig et al 1983). Les effets du jeûne et de la réalimentation sur l'activité lipoprotéine-lipasique sont donc beaucoup plus marqués dans les muscles oxydatifs que dans les muscles glycolytiques, dont le niveau moyen d'activité lipoprotéinelipasique est intrinsèquement beaucoup plus faible (Hocquette et al 1998a), ces muscles utilisant peu d'acides gras.

Chez l'agneau, les activités lipoprotéinelipasiques du tissu adipeux sous-cutané et des muscles glycolytiques et oxydatifs semblent varier selon la densité énergétique de la ration (Andersen et al 1996) : I'activité est plus élevée dans le tissu adipeux et plus faible dans le muscle lorsque le régime est plus énergétique. Chez les ruminants adultes, l'activité lipoprotéine-lipasique des muscles est par ailleurs fortement modulée par les fluctuations du niveau alimentaire (tableau 2). La sous-alimentation diminue l'activité lipoprotéine-lipasique du coeur de vaches (- $66 \%$ ) et de brebis (- $32 \%)$, alors qu'elle n'a pas d'effet significatif dans un muscle squel ettique glycolytique, le Longi ssimus thoracis (tableau 2). A I'in- 
Figure 2. Variations de l'activité lipoprotéine-lipasique dans le muscle cardiaque des espèces monogastriques en réponse à différentes durées de jeûne et à la réalimentation (synthèse de données bibliographiques : Bonnet 1999).

L'effet du jeûne concerne la comparaison de l'activité chez des animaux à jeun et chez des animaux alimentés ad libitum. L'effet de la réalimentation concerne la comparaison de l'activité chez des animaux alimentés ad libitum après une période de jeûne.

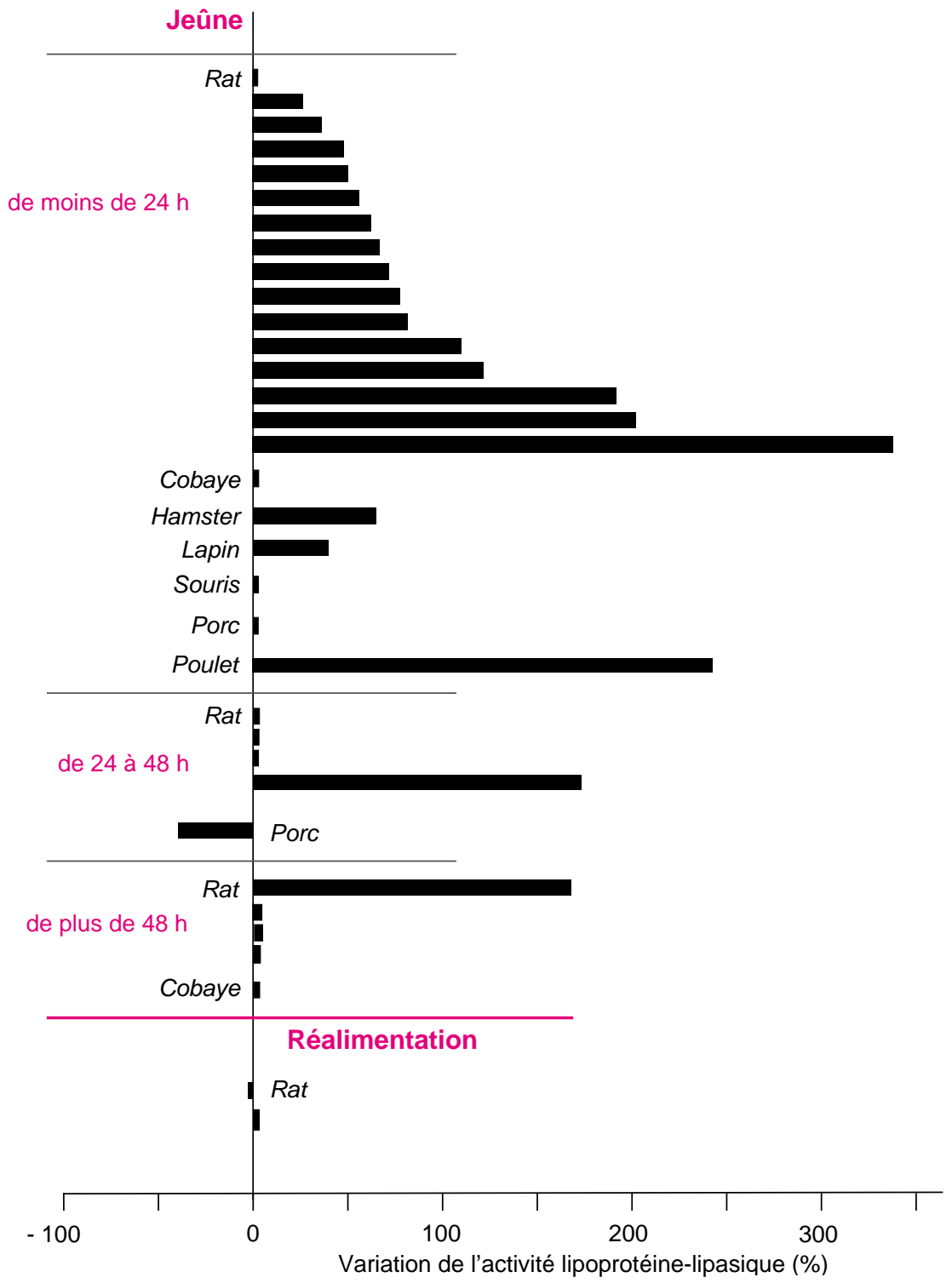

verse, la réalimentation accroît significativement (de +34 à $+258 \%$ ) ces activités dans les deux muscles des deux espèces. Ces résultats sont donc en contradiction avec la plupart des données obtenues chez les rongeurs de laboratoire et notamment dans le cœur de rat. Ces différences sont probablement à relier aux particularités digestives et métaboliques de ces espèces. En effet, chez le ruminant nourri, l'acétate et le glucose sont les principaux substrats énergétiques utilisés par le muscle (Hocquette et al 1998b). Au cours de la restriction alimentaire, la disponibilité de ces substrats diminue, alors que la teneur en acides gras non estérifiés (AGNE) issus de la lipomobilisation augmente (Chilliard \& al 1998a). Chez les ruminants, comme chez les monogastriques, ces AGNE peuvent être utilisés directement par les muscles, ou indirectement après leur transformation hépatique en corps cétoniques. Toutefois, les mécanismes de régulation de la cétogénèse hépatique sont très différents entre les monogastriques et les ruminants (Hocquette et Bauchart 1999). Les AGNE peuvent également être recyclés par le foie en triglycérides, ce qui explique que la triglycéridémie diminue peu (Sudgen et al 1993) ou pas (Björntorp et al 1982) chez le rat à jeun, alors qu'une forte diminution de la triglycéridémie est observée chez les ruminants après une sous-alimentation (Chilliard et al 1998b). Ces divergences entre espèces résultent probablement de la faible capacité des hépatocytes de ruminant à sécréter des triglycérides (Pullen et al 1990) et des lipoprotéines de très faible densité, celle-ci étant au moins 8 fois plus faible chez le bovin que chez le rat (Hocquette et Bauchart 1999). Ceci est à relier aux rôles différents du foie pour la lipogenèse de novo chez ces espèces. Par ailleurs, il existe 
une corrélation inter-espèces entre les réponses de l'activité lipoprotéine-lipasique du cœur durant des périodes de restriction sévère ou de jeûne, et la capacité du foie à sécréter des triglycérides (figure 3). Cette observation permet de mieux comprendre les tendances contradictoires rapportées ci-dessus sur les variations d'activité lipoprotéine-lipasique du cœur des différentes espèces. En effet, elle suggère un lien direct ou indirect entre la nature des substrats énergétiques disponibles pour les tissus (davantage de triglycerides chez le rat à jeun que chez le bovin restreint) et les différences inter-spécifiques de la régulation de l'activité lipoprotéine-lipasique du cœur. Une corrélation, comme celle decrite figure 3, n'a pu être établie pour les variations de l'activité lipoprotéine-lipasique dans les muscles glycolytiques en raison du peu de données disponibles chez les espèces monogastriques.

\section{c / Niveaux de régulation des activités lipoprotéine-lipasiques}

La quantité d'ARNm de la lipoprotéine-lipase dans le tissu adipeux et le cœur de cobaye et de rat varie de manière similaire à son activité en réponse à un jeûne de plus de 24 heures ou à une réalimentation (tableau 3). Une corrélation positive a d'ailleurs été mise en évidence entre les variations de l'activité et du taux d'ARNm de la lipoprotéine-lipase dans le tissu adipeux et les muscles de rat après un jeûne de 24 heures $(r=0,97)$ ou de 6 jours $(r=0,77)$ (Ladu et al 1991). Il existe donc une régulation, au moins en partie prétraductionnelle, de l'expression du gène de la lipoprotéine-lipase chez les monogastriques.

Toutefois, d'autres études montrent que les variations des taux d'ARNm ne sont pas toujours parallèles à celles de l'activité lipoprotéine-lipasique, notamment dans le tissu adipeux et le cœur de rat mis à jeun durant 12 heures (tableau 3). Ces résultats suggèrent que la lipoprotéine-lipase est également soumise à une importante régulation post-transcriptionnelle.

Chez la brebis, nous montrons que le taux d'ARNm de la lipoprotéine-lipase du tissu adipeux périrénal est diminué de $58 \%$ par la sousnutrition, augmenté de $640 \%$ par la réalimentation et qu'il varie de manière parallèle à l'activité lipoprotéine-lipasique, bien que de facon plus marquée pendant la réalimentation (tableau 4). Nous notons, par ailleurs, des variations semblables de l'activité et du taux d'ARNm de la lipoprotéine-lipase dans le cœur de brebis, avec une diminution du taux d'ARNm de $53 \%$ après sous-alimentation et une augmentation de $117 \%$ après réalimentation (tableau 4). Ces résultats quantitatifs sont les premiers obtenus chez les ruminants et confirment la tendance qualitative déjà observée (Bonnet et al 1998a). Ils montrent que la régulation nutritionnelle de l'expression du gène de la lipoprotéine-lipase est au moins en partie pré-traductionnelle, comme cela a été également décrit chez le rat et le cobaye. Ainsi, alors que le sens des régulations de l'activité lipoprotéine-lipasique des tissus adipeux et musculaires semble être liée à l'espèce animale, les niveaux de régulation de l'expression du gène sont comparables chez les différentes espèces étudiées.
Figure 3. Relation inter-espèces entre la capacité du foie à sécréter des triglycérides in vitro et la variation de l'activité lipoprotéine-lipasique dans le muscle cardiaque durant le jeûne ou la sous-alimentation.

La sécrétion de triglycérides a été déterminée par incubation d'explants de foie en présence de ${ }^{14} \mathrm{C}$-palmitate et ${ }^{3} \mathrm{H}$-oléate (Pullen et al 1990). Les réponses de l'activité lipoprotéine-lipasique dans le muscle cardiaque ont été mesurées chez le porc (Enser 1973), la brebis (Bonnet et al 1999), la vache (Faulconnier et al 1999), le cobaye (Enerbäck et al 1988), le lapin (Cryer et Jones 1979), le rat (moyenne et écart type : Borensztajn et al 1970, Cryer et Jones 1979, Doolittle et al 1990, Ladu et al 1991, Sugden et al 1993) et le poulet (Husbands 1972).

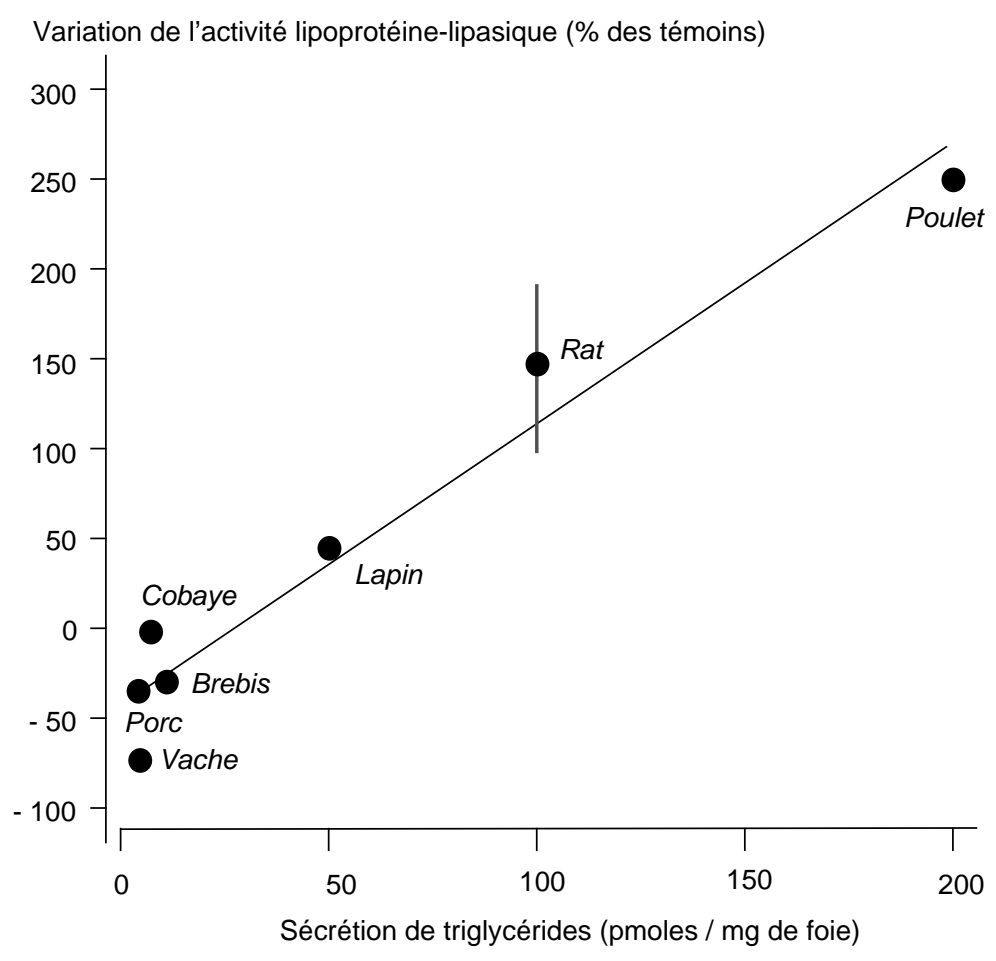

\section{d / Expression tissu-spécifique de la lipoprotéine-lipase}

Chez les ruminants, l'analyse des ARNm de la lipoprotéine-lipase a permis d'identifier deux transcrits dans le tissu adipeux périrénal et le cœur de brebis et de vache (Bonnet et al 1998a et 1999) ainsi que dans le tissu adipeux périrénal et les muscles de veau sevré (Hocquette et al 1998c). Ces résultats corroborent ceux obtenus dans le tissu adipeux humain et de souris (Kirchgessner et al 1987).

La mise au point récente du dosage de I'ARNm de la lipoprotéine-lipase par RT-PCR semi-quantitative en temps réel (Bonnet et al 1998b, Bonnet 1999), nous a permis de quantifier les taux individuels de chacun de ces deux transcrits. Le transcrit de $3,8 \mathrm{~kb}$ est majoritaire dans le cœur alors que celui de 3,4 $\mathrm{kb}$ prédomine dans le tissu adipeux périrénal ovin (figure 4). Ces résultats corroborent ceux obtenus chez le cobaye (E nerbäck et al 1988) et chez l'Homme (Ranganathan et al 1995). Les taux des deux transcrits sont modulés de la même façon par la sous-nutrition et la réalimentation, aussi bien dans le tissu adipeux que dans le cœur (figure 4). II ne semble donc pas y avoir de régulation préférentielle, par le niveau alimentaire, de l'un des deux transcrits au sein d'un même tissu. 
Tableau 3. Niveaux de régulation de l'activité lipoprotéine-lipasique dans les tissus adipeux et musculaires chez les espèces monogastriques au cours du jeûne (comparés aux animaux témoins) et de la réalimentation (comparés aux animaux à jeun).

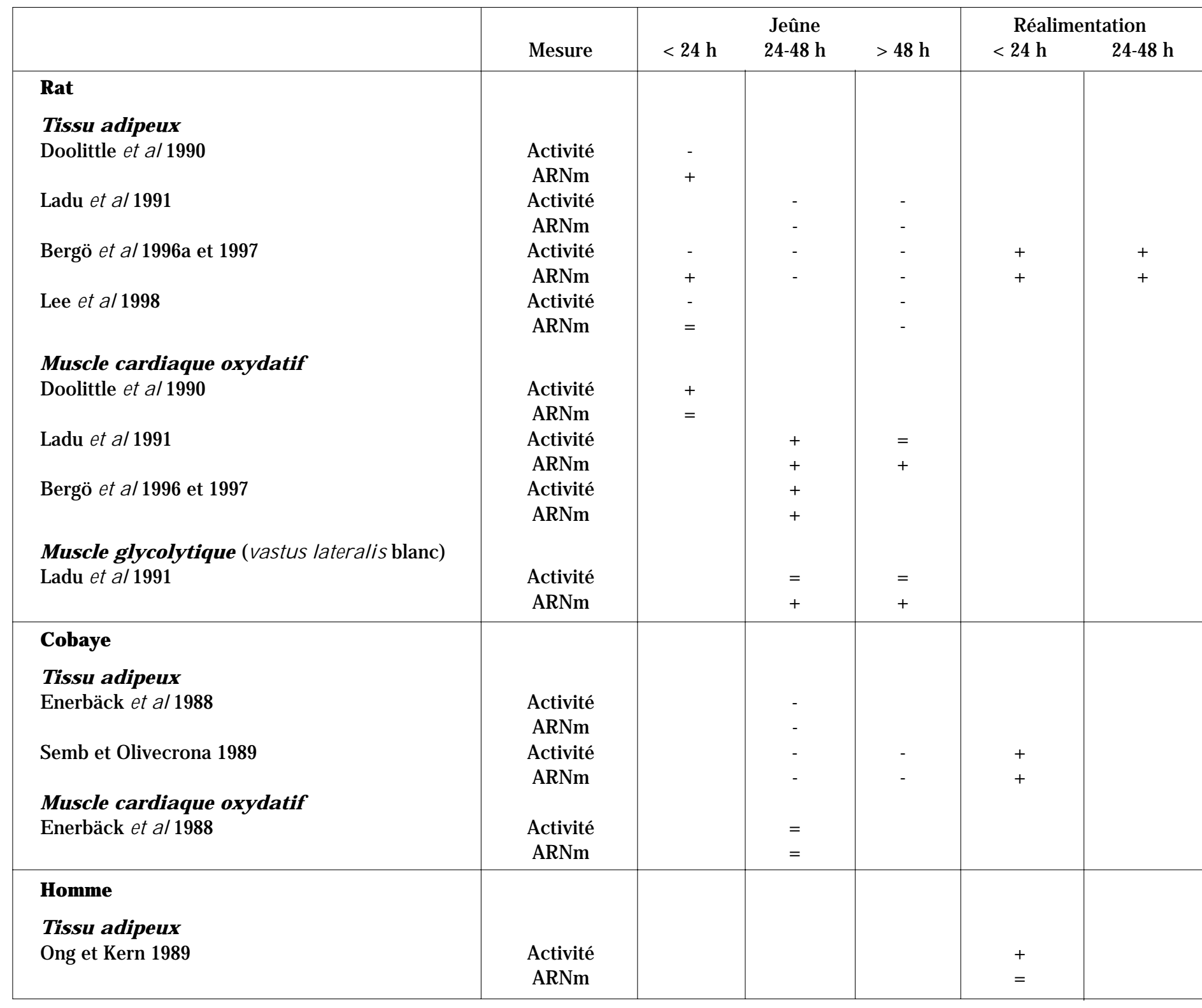

Tableau 4. Effets de la sous-alimentation (en \% des valeurs mesurées chez les animaux témoins) et de la réalimentation (en \% des valeurs mesurées chez les animaux sous-alimentés) sur l'activité et le taux d'ARNm de la lipoprotéine-lipase dans le tissu adipeux périrénal et le muscle cardiaque de brebis (Faulconnier et al 1998, Bonnet et al 1999).

\begin{tabular}{|l|c|c|}
\hline & Sous-alimentation & Réalimentation \\
\hline Tissu adi peux & & +248 \\
Activité & -59 & +640 \\
ARNm & -58 & \\
\hline Muscle cardiaque & & +35 \\
Activité & -32 & +117 \\
ARNm & -53 & \\
\hline
\end{tabular}

\section{2 / E ffets de la photopériode et interactions avec l'état nutritionnel}

Quelques études rapportent des variations saisonnières de l'activité métabolique du tissu adipeux chez les ruminants sauvages tels que le renne (Larsen et al 1985a et 1985b) avec une diminution du dépôt adipeux et de l'activité lipogénique durant I'hiver, diminution concomitante à une moindre ingestion volontaire et à une augmentation du taux plasmatique d'AGNE. La synthèse d'acides gras ainsi que les activités des enzymes lipoprotéinelipase, glucose-6-phosphate déshydrogénase et isocitrate déshydrogénase (enzyme impliquée dans la synthèse de novo d'acides gras) sont par ailleurs diminuées pendant la période de jours courts dans les tissus adipeux des ovins (E isemann et al 1984, Vernon et al 1986) et de hamsters Sibériens (Bartness 1995). De plus, la lipolyse du tissu adipeux stimulée in vi tro par des agents adrénergiques tend à être plus élevée chez des agneaux en croissance placés en jours courts comparativement à ceux placés en jours longs (Eisemann et al 1984). Ces différents résultats suggèrent que la lipogenèse est plus élevée chez les animaux placés en jours longs. En revanche chez le faon, la diminution saisonnière ou artificielle de la durée du jour augmente la prise alimen- 
Figure 4. Expression relative des ARN messagers de la lipoprotéine-lipase dans le tissu adipeux périrénal et le muscle cardiaque chez des brebis témoins $(T)$, sous-alimentées $(S)$ ou réalimentées (R) (Bonnet 1999).

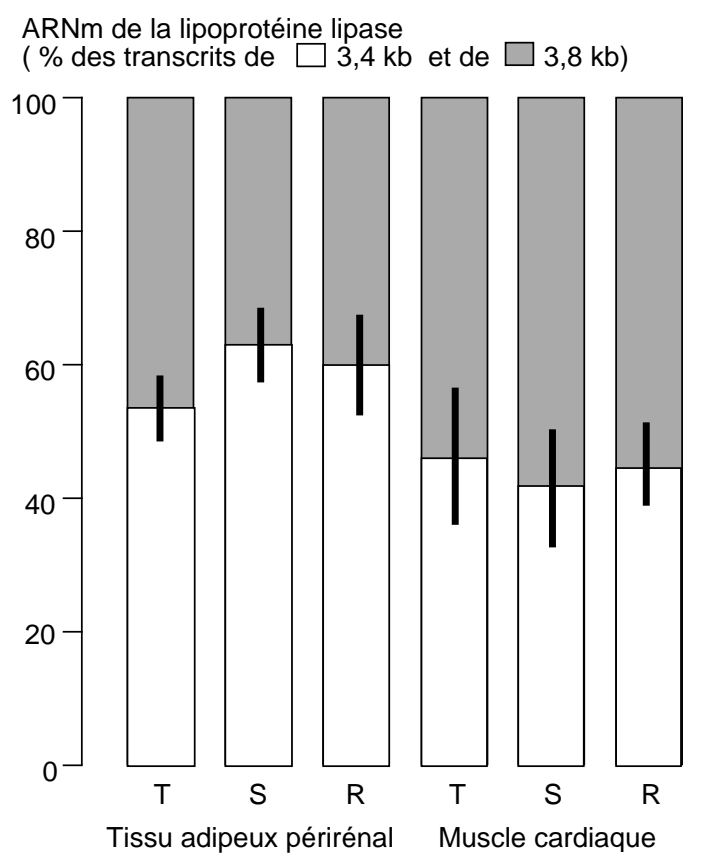

taire et la masse grasse corporelle, ces augmentations étant en partie expliquées par des variations de même sens des activités lipogéniques (Abbott et al 1984).
Dans l'ensemble de ces études, les variations du métabolisme du tissu adipeux sont observées parallèlement à celles de la prise alimentaire et sont accompagnées de variations de l'insulinémie ou des teneurs en métabolites plasmatiques (acétate, glucose, triglycérides, AGNE) connus pour moduler les activités lipogéniques, au moins chez les rongeurs et chez l'Homme. Ainsi, au vu de ces résultats, il est difficile de conclure quant aux effets directs de la photopériode sur le métabolisme du tissu adipeux, ou indirects liés aux variations du niveau d'ingestion ou de la sécrétion d'insuline. C'est la raison pour laquelle nous avons utilisé un modèle expérimental original, permettant d'étudier les effets de la photopériode sur le métabolisme tissulaire, indépendamment de ceux produits sur l'ingestion ou sur l'activité ovarienne, dont les sécrétions hormonales pourraient interagir avec les métabolismes tissulaires (revue de Chilliard 1987). Une expérience a donc été réalisée sur des brebis ovariectomisées, soumises à des traitements photopériodiques contrastés (jours longs, 16 heures de lumière par jour vs. jours courts, 8 heures de lumière par jour) soit en situation de sous-alimentation (apports égaux à $22 \%$ des besoins), soit en situation de réalimentation (190\% des besoins). Chez les brebis placées en jours longs, on observe des augmentations significatives de l'activité de l'enzyme malique dans les tissus adipeux périrénal et sous-cutané, de l'activité lipoprotéine-lipasique dans le tissu adipeux sous-cutané et du taux de transcrits de la lipoprotéine-lipase dans le tissu adipeux périrenal (tableau 5 et figure 5). Toutefois, ces réponses sont plus

Tableau 5. Effets de la photopériode sur les activités lipogéniques et lipoprotéine-lipasique (exprimées en $\mathrm{nmol} / \mathrm{min}$ et par $10^{6}$ adipocytes ou par $\mathrm{mg} A D N$, pour le tissu adipeux ou le muscle, respectivement) et sur le taux d'ARNm de la lipoprotéine-lipase (exprimé en unités arbitraires) dans les tissus adipeux et musculaire chez la brebis adulte sous-alimentée et réalimentée (Bocquier et al 1998, Chilliard et al 1998b, Faulconnier et al 1998, Bonnet 1999).

\begin{tabular}{|c|c|c|c|c|}
\hline \multirow[b]{2}{*}{ Photopériode } & \multicolumn{2}{|c|}{ Sous-alimentée } & \multicolumn{2}{|c|}{ Réalimentée } \\
\hline & courte & longue & courte & longue \\
\hline \multicolumn{5}{|l|}{ Lipoprotéine-lipase } \\
\hline \multicolumn{5}{|l|}{ Tissu adi peux péri rénal } \\
\hline Activité & 158 & 184 & 589 & 604 \\
\hline ARNm & 22 & 32 & 111 & 291 \\
\hline \multicolumn{5}{|l|}{ Muscle cardi aque oxydatif } \\
\hline Activité & 133 & 129 & 187 & 160 \\
\hline ARNm & 71 & 118 & 158 & 252 \\
\hline \multicolumn{5}{|l|}{ Activités des enzymes lipogéniques } \\
\hline \multicolumn{5}{|l|}{ Tissu adi peux périrénal } \\
\hline Synthétase des acides gras & 49 & 44 & 206 & 241 \\
\hline Glucose-6-phosphate déshydrogénase & 149 & 147 & 548 & 576 \\
\hline Enzyme malique & 74 & 87 & 147 & 208 \\
\hline Glycérol-3-phosphate déshydrogénase & 4169 & 3217 & 6625 & 8059 \\
\hline \multicolumn{5}{|l|}{ Tissu adi peux sous-cutané } \\
\hline Synthétase des acides gras & 36 & 60 & 200 & 224 \\
\hline Glucose-6-phosphate déshydrogénase & 147 & 147 & 610 & 663 \\
\hline Enzyme malique & 41 & 51 & 117 & 158 \\
\hline Glycérol-3-phosphate déshydrogénase & 3032 & 4471 & 9128 & 10377 \\
\hline
\end{tabular}


Figure 5. Effets de la durée du jour et de l'état nutritionnel sur l'activité lipoprotéine-lipasique dans le muscle Longissimus thoracis et dans le tissu adipeux sous-cutané, et sur les teneurs plasmatiques en acides gras non estérifiés (AGNE) et en prolactine.

Les apports alimentaires étaient égaux à $22 \%$ des besoins pour les brebis sous-alimentées et à $190 \%$ pour les brebis réalimentées (Bocquier et al 1998, Faulconnier et al 1998).

Jours courts : 8 h lumière / j Jours longs : $16 \mathrm{~h}$ lumière / j

Activité LPL dans le muscle Longissimus thoracis (nmol / $\mathrm{min} / \mathrm{mg} \mathrm{ADN})$
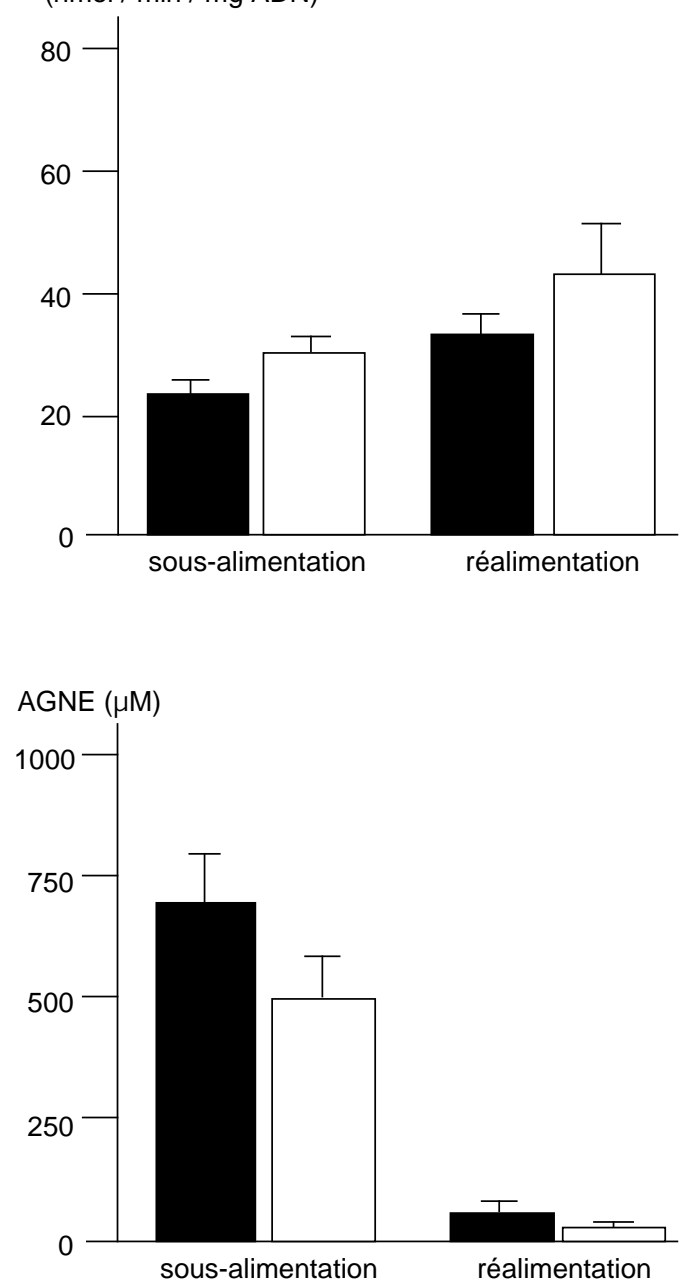

marquées pour les brebis réalimentées que pour les sous-alimentées, du fait d'une interaction (qui tend à être ou est significative) entre les effets de la photopériode et ceux du jeûne ou de la réalimentation. Cette interaction est probablement à relier aux réponses exponentielles des activités lipogéniques lors de l'augmentation des apports énergétiques: une stimulation des activités enzymatiques par les jours longs est mieux détectée lorsque ces activités sont déjà induites par la réalimentation que lorsqu'elles sont inhibées par la restriction.

Chez les brebis placées en jours longs, outre les réponses des activités des enzymes lipogéniques des tissus adipeux, on observe que l'activité lipoprotéine-lipasique augmente dans le muscle Longissimus thoracis, ainsi que le taux de transcrit de la lipoprotéine-lipase dans le cœur (tableau 5 et figure 5). Chez les brebis placées en jours longs et sous-alimentées, ces augmentations des activités lipogéniques se produisent simultanément à
Activité LPL dans le tissu adipeux sous-cutané (nmol / $\min / 10^{6}$ adipocytes)

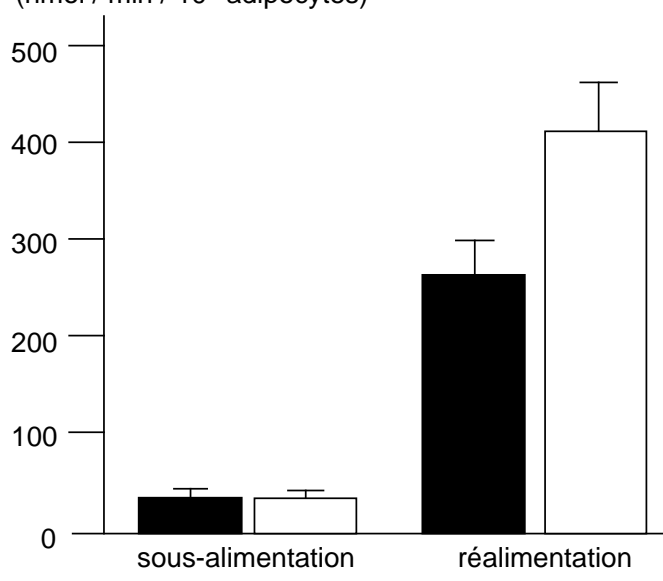

Prolactine $(\mathrm{ng} / \mathrm{ml})$

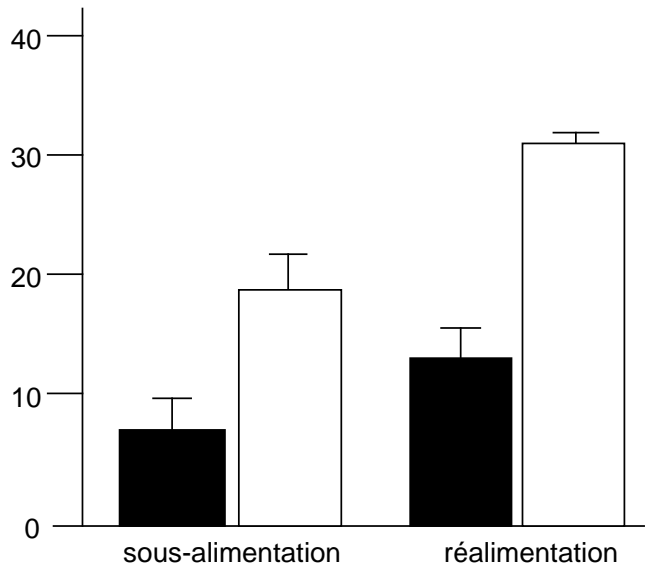

une moindre élévation des teneurs plasmatiques en AGNE (figure 5). Du fait que les teneurs plasmatiques en certains métabolites (glucose, acétate, triglycérides...) et hormones (insuline, GH), ainsi que l'adiposité des brebis n'ont pas été significativement modifiées par la photopériode (Chilliard et al 1998b), ces résultats suggèrent un effet direct de la photopériode sur le potentiel métabolique du tissu adipeux, effet qui se produit dans un délai relativement bref (moins de 6 semaines).

Les médiateurs de cet effet direct restent à définir (revue de Chilliard et Bocquier 1999). On peut envisager que la mélatonine, dont la sécrétion est augmentée en jours courts (revue de Chemineau et al 1996), puisse jouer ce rôle. Cette hypothèse est à relier à l'identification récente de récepteurs à la mélatonine dans le tissu adipeux brun de hamster (Le Gouic et al 1997), dont le rôle physiologique n'est toutefois pas connu. Les variations de prolactinémie pourraient être impliquées 
dans cet effet : Ia lipomobilisation augmente en jours courts lorsque la prolactinémie est faible $(7 \mathrm{ng} / \mathrm{ml})$, et l'activité lipogénique augmente en jours longs, lorsque la prolactinémie est plus élevée (19 ng/ml) (figure 5). Les effets de la prolactine ne seraient toutefois qu'indirects, le tissu adipeux ovin ne contenant pas de récepteurs à cette hormone (Emane et al 1986, Vernon 1989). De plus l'addition in vi tro de prolactine ne modifie ni la lipolyse dans les tissus adipeux ovin et bovin (Houseknecht et al 1996) ou les adipocytes isolés de lapin (Fortun-Lamothe et al 1996), ni la lipogenèse dans le tissu adipeux ovin (Vernon et Finley 1986). Certains auteurs (Frawley et al 1988, English et al 1990) ont toutefois suggéré qu'in vivola prolactine agirait en induisant la synthèse d'un facteur hépatique, la synlactine, dont le rôle physiologique reste à démontrer. Enfin, en jours longs, on observe une augmentation de la leptine circulante et de son ARNm dans le tissu adipeux périrénal (Bocquier et al 1998), qui peut paraître paradoxale puisque cette hormone semble jouer un rôle antilipogénique, mais qui est logique compte tenu du fait que la synthèse de leptine répond généralement aux mêmes stimuli que les voies lipogéniques (revue de Chilliard et al 1999).

Quel que soit le mécanisme incriminé, les effets de la photopériode sur les activités métaboliques du tissu adipeux et des muscles, pour un niveau alimentaire donné semblent coïncider avec les fluctuations saisonnières des disponibilités alimentaires : l'activité lipolytique est accrue en jours courts, alors que les brebis doivent généralement faire face à des situations de pénurie alimentaire en hiver. A l'inverse, la capacité de stockage de lipides corporels et l'hydrolyse des triglycérides par les muscles sont accrues par les jours longs, alors que les disponibilités alimentaires sont élevées au printemps ou en été. Ces mécanismes pourraient permettre aux animaux de mieux anticiper les situations nutritionnelles les plus probables : la reconstitution des réserves (en jours longs et en alimentation favorable) doit primer sur la simple satisfaction des besoins, et la mobilisation des lipides doit permettre de rééquilibrer rapidement le bilan nutritionnel de l'animal lorsque les ressources alimentaires deviennent de plus en plus rares (jours courts et arrivée de l'hiver). Dans le cas des ovins en croissance, chez lesquels l'accrétion protéique répond parfois favorablement aux jours longs (revue de Bauman et al 1982), la stimulation de l'expression du gène de la lipoprotéine-lipase des muscles par les jours longs (suggérée par nos résultats sur brebis adultes) pourrait accroître le captage de lipides par les muscles, surtout oxydatifs. $\mathrm{Ce}$ flux supplémentaire de nutriments énergétiques apportés aux muscles pourrait éventuellement favoriser l'accrétion protéique dans ces tissus, bien que la part des acides gras prélevés et directement oxydés soit faible (Hocquette et al 1998b, Hocquette et Bauchart 1999).

II semble donc que le photopériode soit non seulement le signal principal (proximal) qui conditionne la mise en place de la reproduc- tion chez les brebis (Chemineau et al 1996), mais également un facteur distal qui permette à d'autres fonctions (ingestion, production laitière, dépense énergétique, métabolisme tissulaire) de s'adapter aux fluctuations saisonnières des ressources alimentaires (Bocquier et al 1990), en modifiant les points de consignes des régulations homéostasiques et téléophorétiques qui coordonnent les métabolismes tissulaires en fonction des variations de l'état physiologique et des facteurs environnementaux (Chilliard et Bocquier 1999).

\section{Conclusion et perspectives}

Des changements à court terme de l'état nutritionnel modulent fortement l'activité lipogénique du tissu adipeux chez les ruminants, notamment les activités d'enzymes contrôlant les trois principales voies lipogéniques : la lipogenèse de novo, l'hydrolyse des triglycérides plasmatiques et l'estérification des acides gras. Des variations non négligeables des réponses sont toutefois observées en fonction de différents facteurs : espèce, site anatomique du tissu adipeux, durée et intensité des traitements nutritionnels.

L'étude de la régulation de l'expression du gène de la lipoprotéine-lipase permet une meilleure compréhension des effets des facteurs nutritionnels sur la répartition des nutriments entre les tissus adipeux et les muscles, puisque cette enzyme intervient directement dans le captage d'acides gras par ces tissus. Chez les ruminants, les variations de l'activité lipoprotéine-lipasique des muscles, et plus particulièrement du muscle cardiaque sont parallèles à celles des tissus adipeux, puisque cette activité est diminuée par la restriction et augmentée par la réalimentation. Ces résultats vont à l'encontre de ceux généralement rapportés chez le rat, vraisemblablement en raison d'une adaptation à la faible disponibilité en triglycérides plasmatiques chez le ruminant sous-alimenté, du fait d'un métabolisme digestif et hépatique différent de celui du rat.

Ces études suggèrent donc que les phases de stockage des lipides dans le tissu adipeux sont accompagnées d'une augmentation de l'activité lipoprotéine-lipasique dans les muscles des ruminants, ce qui suggère un rôle pour cette voie métabolique dans le dépôt de lipides intramusculaires et l'accrétion protéique.

Par ailleurs, les variations d'activité lipoprotéine-lipasique dans le tissu adipeux et dans les muscles résultent d'une régulation, au moins en partie, pré-traductionnelle du gène codant pour cette enzyme, chez les ruminants comme chez les monogastriques. Ainsi, les niveaux de régulation de l'expression du gène semblent être comparables chez les différentes espèces étudiees, mais les effets produits sont différents.

Chez les ovins, la durée du jour a un effet positif sur les capacités lipogéniques des tissus adipeux, ainsi que sur l'expression du gène de la lipoprotéine-lipase dans le muscle. La lipomobilisation est, à l'inverse, augmen- 
tée par les jours courts. II serait intéressant de préciser ces résultats en mesurant les effets à long terme de la photopériode dans des dispositifs expérimentaux mimant les fluctuations naturelles de la durée du jour. Ces adaptations métaboliques, bien qu'indépendantes de tout effet préalable sur le niveau d'ingestion, sont probablement impliquées dans les adaptations physiologiques des ovins aux variations saisonnières des disponibilités alimentaires. Ainsi, la conduite alimentaire des petits ruminants pourrait être optimisée en jouant sur la durée d'éclairement des bergeries, selon les saisons et les disponibilités en aliments.
Enfin, les particularités des ruminants font de ces espèces des modèles originaux et productifs pour des études de physiologie comparée sur la régulation des flux de nutriments entre les tissus adipeux et musculaires, en vue d'une meilleure maîtrise de la composition corporelle.

\section{Remerciements}

Les auteurs remercient A. Ollier, I.-P. Pezant, R. J ailler J. Fléchet, M. Tourret, J. Rouel, A. Ferlay, N. Guivier et $F$. Le Provost pour leur participation aux travaux réalisés dans le cadre de l'AIP " Lipogenèse " de I'INRA.

\section{Références}

Abott M.J., Ullrey D.E., Ku P.K., Schmitt S.M., Romsos D.R., Tucker H.A., 1984. Effect of photoperiod on growth and fat accretion in white-tailed doe fawns. J. Wilding management, 48, 776-787.

Andersen M.K., Bailey J.W., Wilken C., Rule D.C., 1996 Lipoprotein lipase and glycerophosphate acyltransferase in ovine tissues are influenced by growth and energy intake regimen. J. Nutr. Biochem., 7, 610-616.

Bartness T.J., 1995. Short day-induced depletion of lipid stores is fat pad- and gender-specific in Siberian hamsters. Physiol. Behav., 58, 539-550.

Bauman D.E., Eisemann J.H., Currie W.B., 1982 Hormonal effects on partitioning of nutrients for tissue growth; role of growth hormone and prolactin. Federation Proc., 41, 2538-2544.

Bergö M., Olivecrona G., Olivecrona T., 1996a. Diurnal rhythms and effects of fasting and refeeding on rat adipose tissue lipoprotein lipase. Am. J. Physiol., 271, E 1092E1097.

Bergö M., Olivecrona G., Olivecrona T., 1996b. Forms of lipoprotein lipase in rat tissues : in adipose tissue the proportion of inactive lipase increases on fasting. Biochem. J., 313, 893-898.

Bergö M., Olivecrona G., Olivecrona T., 1997. Regulation of adipose tissue lipoprotein lipase in young and old rats. Int. J. Obesity, 21, 980-986.

Björntorp P., Edström S., Kral J.G., Lundholm K., Presta E., Walks D., Yang M.U., 1982. Refeeding after fasting in the rat: energy substrate fluxes and replenishment of energy stores. Am. J. Clin. Nutr., 36, 450-456.

Bocquier F., Thériez M., Kann G., Delouis C., 1986. Influence de la photopériode sur la partition de l'énergie nette entre la production laitière et les réserves corporelles chez la brebis traite. Reprod. Nutr. Dev., 26, 389390

Bocquier F., Kann G., Thériez M., 1990. Relationships between secretory patterns of growth hormone, prolactin and body reserves and milk yield in dairy ewes under different photoperiod and feeding conditions. Anim. Prod., 51, 115-125.

Bocquier F., Bonnet M., Faulconnier Y. Guerre-Millo M. Martin P., Chilliard Y., 1998. Effects of photoperiod and feeding level on perirenal adipose tissue metabolic activity and leptin synthesis in the ovariectomized ewe. Reprod. Nutr. Dev., 38, 489-498.

Bonnet M., 1999. Régulation par l'état nutritionnel et la photopériode de l'expression de gènes spécifiant des enzymes du métabolisme énergétique dans le tissu adipeux et le muscle de brebis. Thèse Doct. Univ. Limoges, $100 \mathrm{p}$.

INRA Producti ons Ani males, octobre 1999
Bonnet M., Faulconnier Y., Fléchet J., Hocquette J.F., Leroux C., Langin D., Martin P., Chilliard Y., 1998a. Messager RNAs encoding lipoprotein lipase, fatty acid synthase and hormone-sensitive lipase in the adipose tissue of underfed-refed ewes and cows. Reprod. Nutr. Dev.,38, 297-307.

Bonnet M., Leroux C., Giraud-Delville C., Chilliard Y., Martin P., 1998b. Real time PCR quantification of mRNA encoding key enzymes of lipogenesis. Application to LPL assay in ovine adipose tissue. XXVIth International Conference on Animal Genetics, ISAG, New-Zealand, August 1998, 82 .

Bonnet M., Faulconnier Y., Leroux C., Bocquier F., Martin P., Chilliard Y., 1999. Effect of refeeding on two mRNAs species of lipoprotein lipase in adipose tissue and cardiac muscle of sheep.3rd French-B ritish Meeting on Nutrition, Nancy, 30 Sept-2 Oct, Symposium " Lipogenesis in farm animals ". Proc. Nutr. Soc., in press.

Borensztajn J., Otway S., Robinson D.S., 1970. Effect of fasting on the clearing factor lipase (lipoprotein lipase) activity of fresh and defatted preparations of rat heart muscle. J. Lipid Res., 11, 102-110.

Chemineau P., Malpaux B., Pelletier J., Leboeuf P., Delgadilloj.A., Deletang F., Pobel T., Brice G., 1996. Emploi des implants de mélatonine et des traitements photopériodiques pour maîtriser la reproduction saisonnière chez les ovins et caprins. INRA Prod. Anim., 9, 4560

Chilliard Y., 1987. Variations quantitatives et métabolisme des lipides dans les tissus adipeux et le foie au cours du cycle gestation-lactation. 2. Chez la brebis et la vache. Reprod. Nutr. Dévelop., 27, 327-398.

Chilliard Y., Bocquier F., 1999. Direct effects of photoperiod on lipid metabolism, leptin synthesis and milk secretion in adult sheep. IX th Int. Symp. Ruminant Physiology, Pretoria, 18-22 October 1999, in press.

Chilliard Y., Robelin J., 1985. Activité lipoprotéine-lipasique de différents dépôts adipeux, et ses relations avec la taille des adipocytes chez la vache tarie en cours d'engraissement, ou en début de lactation. Reprod. Nutr. Dévelop., 25 (1B), 287-293.

Chilliard Y., Sauvant D., Morand-F ehr P., 1979. Goat mammary, adipose and milk lipoprotein lipases. Ann. Rech. Vet., 10, 401-403.

Chilliard Y., Sauvant D., Morand-F ehr P., Delouis C., 1987. Relations entre le bilan énergétique et l'activité métabolique du tissu adipeux de la chèvre au cours de la première moitié de la lactation. Reprod. Nutr. Dévelop., 27, 307-308. 
Chilliard Y., Doreau M., Bocquier F., Lobley G.E., 1995 Digestive and metabolic adaptations of ruminants to variations in food supply. In : M. J ournet, E. Grenet, M-H. Farce, M. Thériez, C. Demarquilly (eds), Recent developments in the nutrition of herbivores. Proceedings of the IVth International Symposium on the nutrition of Herbivores, 329-360. INRA E ditions, Paris.

Chilliard Y., Bocquier F., Doreau M., 1998a. Digestive and metabolic adaptations of ruminants to undernutrition and consequences on reproduction. Reprod. Nutr. Dev. 38, 131-152.

Chilliard Y., Faulconnier T., Bonnet M., Bocquier F., 1998b. Mid-term effect of photoperiod on adipose tissue lipogenesis, plasma metabolites, insulin, somatotropin and prolactin in underfed-refed ewes. In : K. MacCracken, E.F. Unsworth and A.R.G. Wylie (eds) Proc. 14 th Symposium on Energy Metabolism of Farm Animal, New castle (Northern Ireland) 14-20 Sept, 67-70. $\mathrm{CAB}$ International.

Chilliard Y., Bocquier F., Delavaud C., Faulconnier Y., Bonnet M., Guerre-Millo M., Martin P., Ferlay A., 1999. La leptine chez le ruminant. Facteurs de variation physiolo giques et nutritonnels. INRA Prod. Anim., 12, 225-237.

Cryer A., J ones H.M., 1979. The distribution of lipoprotein lipase (clearing factor lipase) activity in the adiposal, muscular and lung tissue of ten animal species. Comp. Biochem. Physiol., 63B, 501-505.

DiMarco N.M., Bietz D.C., Whitehurst G.B., 1981. Effect of fasting on free fatty acid, glycerol and cholesterol concentrations in blood plasma and lipoprotein lipase activity in adipose tissue of cattle. J. Anim. Sci., 52, 75-82.

Doolittle M.H., Ben-Zeev O., Elovson J., Martin D., Kirchgessner T.G., 1990. The response of lipoprotein lipase to feeding and fasting. J. Biol. Chem., 265, 4570-4577.

Eisemann J.H., Bauman D.E., Hogue D.E., Travis H.F., 1984. Influence of photoperiod and prolactin on body composition and in vitro lipid metabolism in wether lambs. J. Anim. Sci., 59, 95-104.

Emane M.N., Delouis C., Kelly P.A., Djiane J., 1986 Evolution of prolactin and placental lactogen receptors in ewes during pregnancy and lactation. Endocrinol., 118 695-700.

Enerbäck S., Semb H., Tavernier J., Bjursell G. Olivecrona $T$., 1988. Tissue specific regulation of guinea pig lipoprotein lipase; effect of nutritional state and tumor necrosis factor on mRNA levels in adipose tissue, heart and liver. Gene, 64, 97-106.

English D.E., Russel S.M., Kartz L.S., Nicoll C.S., 1990 Evidence for a role of the liver in the mammotrophic action of prolactin. Endocrinology, 126, 2252-2256.

Enser M., 1973. Clearing-factor lipase in muscle and adipose tissue of pigs. Biochem. J., 136, 381-385.

Faulconnier Y., Bonnet M., Bocquier F., Hocquette J.F. Leroux C., Furet J.P., Martin P., Chilliard Y., 1998. Régulation nutritionnelle et environnementale de l'activité et de l'expression de gènes d'enzymes contrôlant le métabolisme énergétique dans les tissus adipeux et musculaires chez la vache et la brebis adultes. Compte rendu AIP " Lipogenèse ", INRA, $14 \mathrm{p}$

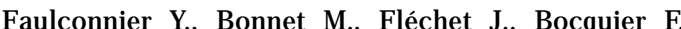
Chilliard Y., 1999. Nutritional regulation of lipoprotein lipase in bovine adipose tissues and muscles.3rd FrenchBritish Meeting on Nutrition, Nancy, 30 Sept-2 Oct, Symposium "Lipogenesis in farm animals ". Proc. Nutr. Soc., in press.

Fortun-Lamothe L., Langin D., Lafontan M., 1996 Influence of prolactin on in vivo and in vitro lipolysis in rabbits. Comp. Biochem. Physiol., 115C, 141-147.
Frawley L.S., Miller H.A., Betts J.G., Simpson M.T., 1988. Liver tissue from lactating rats produces a factor that stimulates prolactin release and gene expression. Endocrinology, 123, 2014-2018.

Giménez M.S., Oliveros de Purlong L., Carrasco de Clementi M., Giménez L.A., Ponce de Ascheri A.M. Alcala U.F., Elorza de Urellano M.E., 1985. Activity of lipogenic enzymes in liver and adipose tissue of goat fed with different diets. Nutrition Reports International, 32, 1131-1137.

Haugebak C.D., Hedrick H.B., Asplund J.M., 1974. Relationship between extramuscular adipose tissue lipoprotein lipase activity and intramuscular lipid deposition in fattening lambs. J. Anim. Sci., 39, 1026-1031.

Hocquette J.F., Bauchart D., 1999. Intestinal absorption, blood transport and hepatic and muscle metabolism of fatty acids in preruminant and ruminant animals. Reprod. Nutr. Dev., 39, 27-48.

Hocquette J.F., Ortigues-Marty I., Vermorel M., 1998a. Nutritional regulation of energy metabolism in growing ruminants. In : J.W. Blum, T. Elsasser and P. Guilloteau (eds), Proc. Symposium on Growth in Ruminants : Basic Aspects, Theory and Practice for the Future, 76-85. University of Berne (Switzerland), 20-22 Août 1998.

Hocquette J.F., Ortigues-Marty I., Pethick D., Herpin P., Fernandez X., 1998b. Nutritional and hormonal regulation of energy metabolism in skeletal muscles of meatproducing animals. Livest. Prod. Sci., 56, 115-143.

Hocquette J.F., Graulet B., Olivecrona T., 1998c. Lipoprotein lipase activity and mRNA levels in bovine tissues. Comp. Biochem. Physiol., 121 (B), 201-212.

Houseknecht K.L., Bauman D.E., Vernon R.G., Byatt J.C., Collier R.J ., 1996. Insulin-like growth factors-I-II, somatotropin, prolactin, and placental lactogen are not acute effectors of lipolysis in ruminants. Domestics Animal Endocrinology, 13, 239-249.

Husbands D.R., 1972. The distribution of lipoprotein lipase in tissue of the domestic fowl and the effects of feeding and starving. Br. Poult. Sci., 13, 85-90.

Ingle D.L., Bauman D.E., Mellenberger R.W., Johnson D.E., 1973. Lipogenesis in the ruminant : effect of fasting and refeeding on fatty acid synthesis and enzymatic activity of sheep adipose tissue. J. Nutr., 103, 1479-1488.

Iritani N., Fukuda H., Tada K., 1996. Nutritional regulation of lipogenic enzyme gene expression in rat epididymal adipose tissue. J. Biochem., 120, 242-248.

Kirchgessner T.G., Svenson K.L., Lusis A.J ., Schotz M.C., 1987. The sequence of cDNA encoding lipoprotein lipase. J. Biol. Chem., 262, 8463-8466.

Kim T.S, Freake H.C., 1996. High carbohydrate diet and starvation regulate lipogenic mRNA in rats in a tissuespecific manner. J. Nutr., 126, 611-617.

Ladu M.J., Kapsas H., Palmer W.K., 1991. Regulation of lipoprotein lipase in adipose and muscle tissues during fasting. Am. J. Physiol., 260, R953-R959.

Larsen T.S., Nilsson N.O., Blix A.S., 1985a. Seasonal changes in lipogenesis in isolated adipocytes from Svalbard and Norwegian reindeer. Acta Physiol. Scand., 123, 53-59.

Larsen T.S., Lagercrantz H., Riemersma R.A., Blix A.S., 1985b. Seasonal changes in blood lipids, adrenaline, noradrenaline, glucose and insulin in Norwegian reindeer. Acta Physiol. Scand., 124, 53-59.

Le Gouic S., Atgié C., Viguerie-Bascands N., Hanoun N., Larrouy D., Ambid L., Raimbault S., Ricquier D.P., Gardiola-Lemaitre B., Pénicaud L., Casteilla L., 1997. Characterisation of a melatonin binding site in Siberian hamster brown adipose tissue. Eur. J. Pharmacol., 339, 271-278.

INRA Producti ons Ani males, octobre 1999 
Lee J.J., Smith P.J., Fried S.K., 1998. Mechanisms of decreased lipoprotein lipase activity in adipocytes of starved rats depend on duration of starvation. J. Nutr. $128,940-946$

Mills S.E ., Lemenager R.P., Horstman L.A., 1989. Effect of suppression of prolactin secretion on adipose lipogenesis in the postpartum beef cow. J. Anim. Sci., 67, 2904-2912.

Ong J.M., Kern P.A., 1989. The role of the glucose and glycosylation in the regulation of the lipoprotein lipase synthesis and secretion in rat adipocytes. J. Biol. Chem., 3177-3182.

Ong J .M., Simsolo R.B., Saghizadeh M., Pauer A., Kern, P.A., 1994. Expression of lipoprotein lipase in rat muscle: regulation by feeding and hypothyroidism. I. Lipid Res., 35, 1542-1551.

Pape M.E., Lopez-Casillas F., Kim K.H., 1988. Physiological regulation of acetyl-CoA carboxylase gene expression : effects of diet, diabetes, and lactation on acetyl-CoA carboxylase mRNA. Arch. Biochem. Biophys., $267,104-109$

Pothoven M.A., Beitz D.C., 1973. Effect of adipose tissue site, animal weight, and long-term fasting on lipogenesis in the bovine. J. Nutr., 103, 468-475.

Pothoven M.A., Beitz D.C., 1975. Changes in fatty acid synthesis and lipogenic enzymes in adipose tissue from fasted and fasted-refed steers. J. Nutr., 105, 1055-1061.

Prior R.L., 1978. Effect of level of feed intake on lactate and acetate metabolism and lipogenesis in vivo in sheep. J. Nutr., 108, 926-935.

Prior R.L., Scott R.A. 1980. Effects of intravenous infusions of glucose, lactate, propionate or acetate on the induction of lipogenesis in bovine adipose tissue. J . Nutr., $110,2011-2019$.

Pullen D.L., Liesman J.S., Emery R.S., 1990. A species comparison of liver slice synthesis and secretion of triacylglycerol from nonesterified fatty acids in media. J. Anim. Sci., 68, 1395-1399.

Quig D.W., Layman D.K., Bechtel P.J ., Hackler L.R., 1983. The influence of starvation and refeeding on the lipoprotein lipase activity of skeletal muscle and adipose tissue of lean and obese Zucker rats. J. Nutr., 113, 1150-1156.

Ranganathan G., Ong J.M., Yukht A., Saghizadeh M., Simsolo R.B., Pauers A., Kern P.A., 1995. Tissue-specific expression of human lipoprotein lipase. Effect of the 3'untranslated region on translation. J. Biol. Chem., 270, 7149-7155.

Sebastian I., Chilliard Y., Purroy A., Jaime C., 1993. Supplémentation en céréales, état corporel et enzymes lipogéniques du tissu adipeux chez la brebis Aragonesa. Ann. Zootech., 42, 299-313.

Semb H., Olivecrona T., 1989. Two different mechanisms are involved in nutritional regulation of lipoprotein lipase in guinea-pig adipose tissue. Biochem. J ., 262, 505-511.

Smith S.B., Prior R.L., Mersmann H.J., 1983. Interrelationships between insulin and lipid metabolism in normal and alloxan-diabetic cattle. J. Nutr., 113, 1002 1015.

Smith S.B., Prior R.L., Koong L.J., Mersmann H.J . 1992 Nitrogen and lipid metabolism in heifers fed at increasing levels of intake. J. Anim. Sci., 70, 152-160.

Sugden M.C., Holness M.J ., Howard R.M., 1993. Changes in lipoprotein lipase activities in adipose tissue, heart and skeletal muscle during continuous or interrupted feeding. Biochem. J ., 292, 113-119.

Tan M.H., Sata T., Havel R.J., 1977. The significance of lipoprotein lipase in rat skeletal muscle. J. Lipid Res., 18 363-369.

Tume R.K., Thornton R.F., Johnson G.W., 1983 Lipoprotein lipase of sheep and rat adipose tissues. Aust. J. Biol. Sci., 36, 41-48.

Vernon R.G., 1989. Endocrine control of metabolic adaptation during lactation. Proc. Nutr. Soc., 48, 23-32.

Vernon R.G., Finley E., 1986. Endocrine control of lipogenesis in adipose tissue from lactating sheep. Biochemical society transactions, 616 th meeting London, 635-636.

Vernon R.G., Clegg R.A., Flint D.J ., 1986. Adipose tissue metabolism in sheep : response to season and its modulation by reproductive state. Horm. Metabol. Res., 18 308-312.

Youngstrom T.G., Bartness T.J ., 1995. Catecholaminergic innervation of white adipose tissue in Siberian hamsters Am. Physiol. Soc., 268, R744-R751.

\section{Abstract}

Regulation of lipid metabolism of adipose tissue and muscle in ruminants. E ffects of feeding level and photoperiod.

The respective effects of feeding level and photoperiod variations on lipid metabolism and nutrient partitioning between ruminant adipose tissue and muscle are reviewed, with a particular interest in lipogenic enzymes and lipoprotein lipase gene expression in the cow and the ewe. Underfeeding decreases de novo fatty acid synthesis and lipoprotein lipase activity in adult and growing ruminant adipose tissues. R efeeding partially or totally reverses these effects. The lipoprotein lipase activity is not modified by underfeeding in the glycolytic Longissimus thoracis muscle, but is decreased in the oxidative cardiac muscle of adult ovine and bovine animals. Refeeding increases lipoprotein lipase activity in these two muscle types. Feeding level alters lipoprotein lipase in the same way in adipose tissues and muscles of ruminants, contrary to observations usually made in the rat. However, variations in lipoproINRA Producti ons Ani males, octobre 1999 tein lipase mRNA level in adipose tissue and muscle are parallel to those of lipoprotein lipase activity in the different animal species. These results at least partly suggest a pretranslational regulation in the expression of the lipoprotein lipase gene. Photoperiod directly affects adipose tissue and muscle metabolic activities in ewes. Indeed, lipogenic capacities in adipose tissue and lipoprotein lipase activity in glycolytic muscle are increased by long days. Inversely, lipomobilisation is increased by short days. These metabolic adaptations are probably involved in physiological adaptations of ewes to seasonal changes in food availability.

FAULCONNIER Y., BONNET M., BOCQUIER F., LEROUX C., HOCQUETTE J.-F., MARTIN P., CHILLIARD Y., 1999. Régulation du métabolisme lipidique des tissus adipeux et musculaires chez le ruminant. Effets du niveau alimentaire et de la photopériode. INRA Prod. Anim., 12, 287-300. 